\title{
ANÁLISIS DE LAS ESTRATEGIAS DIDÁCTICAS PARA EL DISEÑO, SELECCIÓN, PRODUCCIÓN, UTILIZACIÓN Y VALIDACIÓN DE RECURSOS EDUCATIVOS AUDIOVISUALES INTERACTIVOS EN UNA INSTITUCIÓN EDUCATIVA. ESTUDIO INICIAL
}

\author{
José Hidalgo Navarrete \\ Centro Universitario "Sagrada Familia” (Adscrito a la Universidad de Jaén) \\ jhidalgo@ujaen.es. ORCIC: 0000-0002-2721-5007 \\ Emerio Aliaga Zegarra \\ Universidad Internacional Iberoamerica (UNINI) (México) \\ emerio45@yahoo.es.
}

\begin{abstract}
Resumen. Es evidente el constante cambio que sufre nuestro entorno, modificaciones en el clima, nuevas infraestructuras y, sobre todo el avance tecnológico, el cual contribuye al desarrollo de las ciencias, la creación de nuevos inventos y avances en los medios audiovisuales, entre otros. Estos últimos roban cada vez más atención a muchas personas, principalmente a las nuevas generaciones. Todo a nuestro alrededor evoluciona y la educación no puede quedarse atrás; el estudiante se interesa mucho más por internet, la televisión, los móviles y el cine, entre otros, dedicando menos tiempo a las labores académicas. La solución de dicho problema no está en prohibirlos sino en aprovecharlos para beneficio del proceso formativo. Frente a esta situación en el presente trabajo de investigación se examina: la existencia, estado y el uso de los recursos audiovisuales interactivos en el proceso enseñanza-aprendizaje y su relación con el rendimiento académico de los alumnos, el trabajo docente y la eficiencia de una institución educativa de la zona sur de la comunidad de Madrid. Igualmente se explora el uso real que se da de este tipo de recursos de educación y la opinión que tienen los docentes al respecto. Para ello se ha diseñado un cuestionario con tres bloques (dimensiones), validado para este fin. Los resultados muestran que se utilizan los Recursos Audiovisuales interactivos y su selección y validación, siguiendo criterios pedagógicos que influyen de manera positiva en el aprendizaje.
\end{abstract}

Palabras clave: análisis, selección, recursos audiovisuales educativos.

\section{ANALYSIS OF THE TEACHING STRATEGIES FOR THE DESIGN, SELECTION, PRODUCTION, UTILIZATION AND VALIDATION OF INTERACTIVE AUDIOVISUAL EDUCATIONAL RESOURCES IN AN EDUCATIONAL INSTITUTION. INITIAL STUDY}

\begin{abstract}
It is obvious that our environment is undergoing a constant transformation including climate changes, new infrastructures and especially technological progress, which contributes to sciences development and the creation of new inventions and audiovisual media advances. The latter steal more and more attention from many people, mainly the new generations. Everything around us evolves and education cannot be left behind; students are much more interested in internet, television, mobile phones and movies among others, spending less time in academic work. The solution to this problem is not to forbid these channels but to integrate them in the educational process. Facing this context, the present research examines the existence, status and use of interactive audiovisual resources in the teaching-learning process. Likewise, its relationship with the academic performance of the students, the teaching work and the efficiency of an educational institution of the southern area of Madrid's community. It also explores the real use of this type of educational resources and the teachers' point of view on this matter. To this end, a questionnaire with three sections (dimensions) has been designed and validated. The results demonstrate that Interactive
\end{abstract}


Audiovisual Resources are selected and validated following pedagogical criteria and they are actually used as an educative tool having a positive impact on the learning process.

Keywords: analysis, selection, educational audiovisual resources.

\title{
ANÁLISE DAS ESTRATÉGIAS DE ENSINO PARA O PROJETO, SELEÇÃO, PRODUÇÃO, UTILIZAÇÃO E VALIDAÇÃO DE RECURSOS EDUCACIONAIS AUDIOVISUAIS INTERATIVOS EM UMA INSTITUIÇÃO EDUCACIONAL. ESTUDO INICIAL
}

\begin{abstract}
Resumo. A constante transformação do nosso ambiente é evidente, principalmente no que toca a alterações climáticas, novas infrastruturas e, sobretudo, avanços tecnológicos que contribuem para o desenvolvimento científico, a criação de novas invenções e avanços dos meios de comunicação audiovisuais. Este último atrai cada vez mais a atenção de muitas pessoas, nomeadamente as novas gerações. Tudo ao nosso redor evolve e a educação não pode ser deixada para trás; alunos estão cada vez mais interessados na internet, televisão, telemóveis e filmes, entre outros, dedicando cada vez menos tempo ao trabalho académico. A solução para este problema não passa por proibir estes meios, mas sim por integrá-los no processo educacional. Face a este contexto, a presente investigação avalia a existência, o estatuto e o uso de recursos audiovisuais interativos no processo de ensino-aprendizagem, bem como a sua relação com o aproveitamento académico dos alunos, o trabalho docente e a eficiência de uma instituição educacional da zona sul da comunidade de Madrid. Também avalia o uso prático desde tipo de recursos educacionais e o ponto de vista dos professors relativamente a este assunto. Como tal, um questionário composto por três secções foi preparado e validado. Os resultados demonstram que recursos audiovisuais interativos são selecionados e validados segundo critérios pedagógicos e acabam por ser utilizados como uma ferramenta educativa com um impacto positivo no processo de aprendizagem.
\end{abstract}

Palavras-chave: análise, seleção, recursos audiovisuaiseducacionais.

\section{Introducción}

Existe una extensa y variada información sobre el papel que juegan los Recursos Audiovisuales Interactivos Didácticos en el trabajo docente en el aula, así como teorías que sostienen y relacionan a estos medios con el sistema educativo. Este estudio se orienta a comprobar el conocimiento que tienen los docentes de estos recursos a la hora de su selección, tratando de determinar la influencia que estos medios tienen frente a la mejora del rendimiento académico de los alumnos, lo que va a contribuir a la eficiencia de la institución educativa.

La presencia de Recursos Audiovisuales en las instituciones escolares ha aumentado considerablemente, por los esfuerzos realizados desde los propios centros y puestos en funcionamiento por las diferentes Administraciones Educativas. Sin embargo, los criterios que se siguen manejando para su utilización, se apoyan más en principios administrativos, de costumbre, experienciales y operativos que en otros que pudiéramos denominar técnico - didácticos y curriculares. Igualmente, el medio o recurso audiovisual está cada vez más presente en el ámbito informal y formal del alumnado, tanto en el uso cotidiano como en la escuela. Para su inclusión, es evidente que hay que cumplir con una serie de principios metodológicos que lleven a su integración en los procesos de enseñanza y aprendizaje (Ballesteros Regaña, 2016). A través de las múltiples pantallas que rodean a los estudiantes, el acceso a recursos audiovisuales es ubicuo, sobre todo, a través de los dispositivos móviles que los alumnos poseen. Las tabletas y los móviles inteligentes se convierten en pequeñas salas de cine o televisiones portátiles en los propios bolsillos del alumnado. No solo posibilitan el acceso, sino también la propia producción 
audiovisual de los más jóvenes, convirtiéndose así en prosumidores (productor + consumidor).

Esto lleva a pensar en la necesidad de propiciar e impulsar una reflexión sobre cómo y por qué estos recursos deben ser utilizados en el currículum (Somekh, 2007, Goig, 2009, Chick, 2011, Haan, 2011, Expósito y Manzano, 2010 y 2013, Manzano, 2012). Se ha asumido que deben introducirse, y que esto automáticamente significa una innovación en el terreno educativo y repercute en un aumento, cuantitativo y cualitativo, de la transmisión de información y del procesamiento de la misma por el alumno, creando entornos más favorables para el aprendizaje.

Para los jóvenes, el lenguaje multimodal forma parte de su comunicación diaria, ya que prolifera el uso de selfies, Memes, gifs y todo tipo de imágenes y vídeos a través de redes sociales. Entre las tendencias actuales cabe destacar la aplicación para la creación de videoclips con el móvil que es un claro ejemplo de la creación de mensajes multimodales. La captura del vídeo se hace a modo de selfie y con una serie de movimientos específicos con el móvil y la letra de la canción se acompaña con un lenguaje de signos. Las plataformas que de forma exclusiva tienen el medio audiovisual como protagonista (Instagram, Snapchat y últimamente Tic Toc) se encuentran cada vez más en auge, creciendo su uso de forma exponencial.

En el ámbito educativo se emplea el formato audiovisual en diferentes asignaturas o como propio objeto de estudio. El uso específico de documentos audiovisuales por parte de profesores es una práctica bastante común para ilustrar asignaturas y ayudar en la comprensión de conceptos. Sin embargo, el aprendizaje reflexivo y crítico sobre productos mediáticos o audiovisuales es un ejercicio poco común, aunque necesario, ante la predominancia del lenguaje visual en las comunicaciones interpersonales de los más jóvenes, ya que son cada vez más accesibles y el conocimiento más democrático; por esa razón, el futuro de la educación ineludiblemente está ligado a los Recursos Audiovisuales y a su potencial interactivo y multimedia.

Los RAI Didácticos, sean manipulativos o virtuales, pueden ser el soporte para el planteamiento de problemas y situaciones didácticas que promuevan la actividad y reflexión en todas las asignaturas. Como tales recursos, tienen unas potencialidades que deben ser hechas realidad por el profesor, lo cual no es inmediato, ya que no es suficiente con el enunciado de las tareas, sino que es necesario identificar e implementar los conocimientos y la trayectoria de estudio correspondiente. Es decir, cobran una gran importancia en el aula como herramientas educativas (Segura Morrero, 2014) siempre que su selección se haga de manera adecuada y siguiendo unos criterios estrictamente pedagógicos. Es ingenuo pensar, como se supone en ciertas posiciones constructivistas sobre el aprendizaje, que el alumno aprende interactuando con los recursos y resolviendo problemas, sin tener en cuenta el papel tanto de las interacciones entre los estudiantes como el papel del profesor-guía. Los conocimientos se generan a partir de la resolución de problemas, pero no se reducen a los problemas y técnicas de solución; el progreso, tanto individual como colectivo del alumno, tiene lugar cuando se logran generalizar y justificar los procedimientos de solución a tipos de problemas cada vez más amplios. Esto plantea un reto a los profesores, formadores de profesores e investigadores en educación ya que la incorporación de estos recursos en el estudio no es inmediata ni transparente.

Según Almerich, Suárez, Orellana y Díaz (2010), existe un bajo nivel de integración de las TIC en las clases y los factores a tener en cuenta, tanto para la evaluación de sus efectos como de las condiciones de implementación. Se constata una tensión entre las altas expectativas del uso de las TIC para favorecer la enseñanza y el aprendizaje y la baja integración en las clases. Parece necesario abordar el tema desde 
nuevas perspectivas que ayuden a comprender este fenómeno.

La elaboración de criterios de uso, así como herramientas de análisis de las consecuencias instruccionales y cognitivas de su empleo en procesos de enseñanza aprendizaje continúa siendo una cuestión abierta. Como afirma Masalski (2005, p. ix), "encontrar modos efectivos de usar la tecnología para la enseñanza, aprendizaje y evaluación, todavía puede ser una tarea desalentadora".

\section{Marco teórico}

Los últimos diez años han sido fecundos en avances tecnológicos aplicables a la educación para ofrecer lo mejor y más importante en experiencias para los alumnos y hacerlo extensivo a un número cada vez mayor. Está comprobado que el uso de la multimedia mejora el aprendizaje de los alumnos y reduce el tiempo de instrucción y los costos de la enseñanza (Barros, 2015). Las razones de esta situación están en los diferentes factores que repercuten en la utilización de los medios por parte de los profesores: facilidad de acceso, cultura tecnológica y estructura organizativa del centro, formación del profesorado, apoyo técnico, ideología y actitudes del profesorado. Se concluye también que las tecnologías de la información y las comunicaciones es un producto de la era de la globalización que, sin duda, está al alcance de los individuos y forma parte de sus vidas, de ahí la importancia de su uso en la educación. Además, los medios audiovisuales tienen una importancia trascendental desde el punto de vista didáctico, ya que debe asumirse por cada académico, enseñarse a partir de los mismos, (Barros, 2015), y tener en cuenta que, tendrían que ver con la utilización de los medios precedida de un análisis y comprensión de los significados construidos o su uso como herramientas de investigación. Así pues, la pretensión de conseguir una metodología de enseñanza más activa y participativa, más creativa, más crítica ante los mensajes audiovisuales, más rica en canales de expresión, etc., se ve ciertamente frustrada.

Posteriormente, a consecuencia del desarrollo de la informática, se va introduciendo en el mundo del audiovisual la digitalización y la interactividad que ésta conlleva. Así surgen los denominados hipervídeos, caracterizados por ampliar la información de la secuencia del video conductor, a través de diversos recursos complementarios que pueden adoptar cualquier formato de archivo y que van ligados al vídeo conductor mientras éste se desarrolla (García Valcárcel, 2008; García Matamoros, 2014). Así mismo, el auge de las redes de comunicación y la apuesta por la colaboración a través de las mismas, posibilita el nacimiento de nuevos proyectos para compartir los recursos audiovisuales.

También Internet y la expansión de la enseñanza virtual potencian el uso de la video-conferencia, como un medio de comunicación audiovisual al que se le puede asignar una finalidad educativa, utilizado fundamentalmente en los procesos de elearning, para favorecer los procesos de interacción entre profesor y alumno, proporcionando acceso a los elementos paralingüísticos de la comunicación. Un análisis de las posibilidades de esta herramienta es la que nos presentan Alonso y Gallego (2007) y Prendes y Castañeda (2007), y algunas experiencias llevadas a cabo como son las publicadas por Saez - López, y Ruiz-Gallardo, (2014), González, Cobo y Rodríguez, (2014) y Martínez y Gómez, (2015).

Entre los diversos recursos también debemos mencionar el cine y la televisión como recursos audiovisuales que, si bien generalmente no son diseñados con finalidad instructiva, sí pueden ser estímulos para el aprendizaje. Diversos autores han señalado las posibilidades didácticas de estos recursos para trabajar contenidos no sólo conceptuales sino también, y, sobre todo, procedimentales y actitudinales (González García, 2015; García y Nadal, 2015; Pascual y Ortega, 2007; Pellicer, 2014; Petit y Solbes, 2015). 
Así mismo se ha desarrollado el concepto de inteligencia fílmica, en el marco teórico de las inteligencias múltiples (Mesa, 2015), que considera la inteligencia como el potencial psicobiológico para resolver problemas o crear nuevos productos que tienen valor en su contexto cultural. En este contexto se define la inteligencia fílmica como la capacidad de los niños para la comprensión argumental y la discriminación ética y estética de los contenidos transmitidos a través de los diferentes sistemas multimedia (De Andrés et al., 2011). Se parte de la hipótesis de que la imagen audiovisual supone un importante elemento modificador de la conducta perceptiva y cognitiva infantil. La medición de la inteligencia fílmica se plantea a través de las siguientes dimensiones: a) Inteligencia lógica: capacidad para comprender la estructura y secuenciación de una narración cinematográfica, b) Inteligencia de aprendizaje: capacidad para recordar comprensivamente lo asimilado a través del recurso audiovisual (retención $\mathrm{y}$ transferencia), c) Inteligencia emocional: capacidad de distinguir con claridad los mensajes afectivos, d) Inteligencia moral: capacidad de comprensión de los valores o contravalores transmitidos.

Algunos de los proyectos más interesantes que se están desarrollando sobre recursos audiovisuales, con vistas a su incorporación en los procesos de innovación educativa están centrados en el diseño de videojuegos educativos (seriousgames) y procesos de gamificación (Gallego, Molina y Faraón, 2014; Prieto, Díaz, Monserrat y Reyes, 2014; Scolari, 2013; Lacasa, 2011; Revuelta y Esnaola, 2013) así como en el uso de la realidad aumentada (Fombona, Pascual y Madeira, 2012; Moralejo, Sanz, Pesado y Baldassarri, 2014). Todos estos recursos audiovisuales hay que analizarlos en el marco de la sociedad actual, caracterizada por la abundancia de estímulos sensoriales, icónicos y sonoros, y en la que las personas, cada vez más, tienen una necesidad básica de hiperestimulación sensorial, especialmente los más jóvenes. Los recursos audiovisuales suponen una forma de comunicación multisensorial, al implicar una multiplicidad de códigos que inciden sobre diversos sentidos y formas de percepción. Aquí estriba la potencia comunicativa de lo audiovisual. Algunos códigos apelan fundamentalmente a lo emotivo, como la imagen y la música, mientras que otros inciden en la parte más racional de nuestro pensamiento, como el lenguaje verbal. La eficacia comunicativa de los mensajes audiovisuales, tal como señala García - Valcárcel et al. (2015), estará condicionada por la correcta integración de todos estos códigos y lenguajes.

La imagen se ha utilizado desde los tiempos más remotos como medio para la enseñanza y el aprendizaje, de gran utilidad porque se decodifica de forma automática, desde la sensibilidad y emotividad. En el ámbito escolar las imágenes también han estado siempre presentes, en forma de ilustraciones, mapas, figuras, cuadros, maquetas; el lenguaje audiovisual permite un aprendizaje peculiar a partir de las emociones para, en un proceso de distanciamiento gradual, llegar a las significaciones, a las ideas y a los conceptos (Álvarez, 2014; García, Arellano y Ruiz, 2014; García Valcárcel y Hernández, 2013).

\section{Problema objeto de estudio}

Si tenemos en cuenta los diferentes estudios realizados con respecto al uso de los medios audiovisuales, encontramos que en los resultados obtenidos se evidencian las ventajas y limitaciones de estos, expresado en forma general por Marín (2008), Fernández Botanero (2010) como motivadores y reforzadores del aprendizaje, independientemente del nivel de enseñanza en el que desarrollen su docencia.

Citado por Hernández y Quintero (2009), Área (2000) manifiesta que la incorporación de los nuevos recursos tecnológicos en las prácticas docentes no ha 
conllevado una innovación pedagógica profunda en los objetivos, en las metodologías, en los roles y funciones docentes, ni siquiera en la actividad de aprendizaje de los alumnos. El proceso de integración de las TIC en las escuelas e institutos españoles no parece que haya promovido todavía un uso habitual de estas tecnologías por parte de la mayoría de alumnos y profesores, ni que su utilización haya desencadenado cambios significativos en los objetivos educativos, ni en la forma que los alumnos aprenden (Sigalés, Mominó, Meneses y Badia, 2009). Esta cuestión que puede ser no excesivamente preocupante hoy en día, puede empezar a serlo en el futuro si, como ha sucedido en otros países con una mayor inversión en recursos tecnológicos, donde se confirma que el uso de las TIC en las aulas tiende al estancamiento.

Todo ello pasaría por admitir, una vez más, que un factor clave, aunque no el único, para la integración de los medios tecnológicos en la enseñanza es la formación del profesorado, pero es necesario que dicha formación vaya más allá de la alfabetización tecnológica y contemple el desarrollo de competencias en el profesorado de cara a optimizar el uso didáctico de los recursos.

Por ello, las interrogantes que podríamos hacernos respecto a las necesidades formativas en la integración de las TIC en el diseño y desarrollo curricular son muchas y, a veces, no tan fáciles de resolver o contestar. Centrándonos en la institución objeto de estudio se podrían plantear, entre otras, las siguientes preguntas:

1. ¿Qué estrategias emplean los docentes de una Institución Educativa para el diseño, producción y validación de recursos audiovisuales interactivos y qué relación hay con el rendimiento escolar?

2. ¿Con que frecuencia los docentes de la Institución Educativa usan los recursos audiovisuales interactivos en el proceso de enseñanza - aprendizaje y qué relación tiene con el rendimiento escolar?

3. ¿Cuáles son las exigencias didácticas que orientan el diseño, producción, validación y uso de recursos audiovisuales interactivos, tomados en cuenta por los profesores de la Institución y su relación con el rendimiento escolar?

4. ¿En qué medida las decisiones tomadas sobre el uso de los recursos audiovisuales didácticos en las clases dan lugar a un servicio más eficiente?

5. ¿Qué recursos considera imprescindibles el docente para realizar con comodidad y calidad su tarea educativa?

\section{Metodología}

Para la realización del presente estudio, en el que se pretenden poner en relieve las actitudes y consideraciones previas que usan los docentes de una región de la Comunidad de Madrid (España) a la hora de hacer la selección de los recursos audiovisuales para la impartición de sus clases, se ha usado una metodología fundamentalmente cuantitativa en la que se ha usado un cuestionario para la recogida de datos. Dicho cuestionario, previamente ha sido sometido a "juicio de expertos" así como se le ha calculado el Alpha de Cronbach $(7,03)$ para verificar la validez del mismo.

Como hemos dicho, anteriormente, el objetivo de la investigación es identificar las exigencias didácticas para el diseño, selección, producción, validación y uso de recursos audiovisuales interactivos didácticos a nivel de docentes de una región de la Comunidad de Madrid, con el fin de mejorar el rendimiento escolar (que serán comparados con otros centros educativos en estudios posteriores y determinar así la localidad o no de estos resultados), así como detectar si para esa selección y uso, realmente se tienen en cuenta unos determinados criterios, de forma sistemática, o bien es un proceso algo más aleatorio. 


\section{Hipótesis}

Para el desarrollo de nuestra investigación, se propusieron dos hipótesis iniciales que se llevaron a comprobación a través de todo el proceso:

$\mathbf{H}_{1}$. La identificación, selección y aplicación adecuada de las exigencias didácticas por los docentes en el diseño, producción y validación de los recursos audiovisuales interactivos didácticos determinan la eficacia para mejorar el rendimiento escolar.

$\mathbf{H}_{2}$ El uso programado de recursos audiovisuales interactivos didácticos, por los docentes, incide en una eficacia para lograr un mejor rendimiento escolar y trabajo docente.

\section{Herramientas de recogida de información}

Como ya se ha mencionado con anterioridad, el instrumento con el cual se llevó a cabo la recopilación de datos fue un cuestionario que consta de 60 preguntas, estructurales, no generales, referentes a los diferentes requerimientos de la identificación, selección y uso adecuado de los recursos audiovisuales en las aulas.

La encuesta ha sido construida ad hoc para el presente estudio, la cual antes de su aplicación ha sido validada mediante juicio de expertos (cinco) integrados por: docentes propiamente dichos en activo, con funciones tanto de docencia como de gestión dentro de los centros educativos y la Consultora Educativa APPLE, como agente externo para esa validación. Esta consultora ha trabajado con los centros para la aplicación del IPad en el proceso de enseñanza-aprendizaje en el curso escolar 2017 - 2018 en quinto y sexto de educación primaria, y generalizar su aplicación en toda la etapa de 6-12 años, para los próximos periodos escolares.

El informe que debían elaborar los jueces consta de cinco apartados en los que se valora una determinada dimensión en cada uno de ellos. Estas cinco dimensiones son la de pertinencia y relevancia del instrumento, claridad del instrumento, suficiencia del mismo para medir lo que se desea, aplicabilidad del mismo tal cual y por último, la aplicabilidad después de su corrección. En una escala de 5 a 10, las dimensiones de Pertinencia y Relevancia del Instrumento han sido valoradas con nueve por el $100 \%$ de los expertos; la dimensión claridad del instrumento ha sido valorada con siete por el 100 $\%$ de los expertos; las dimensiones suficiencia y aplicable han sido valorados con ocho por el $100 \%$ de los expertos y la dimensión aplicable después de corregir ha sido valorada con nueve también por el $100 \%$ de los expertos. Además, como ya hemos mencionado anteriormente, se le calculó el coeficiente Alpha de Cronbach con el paquete estadístico SPSS V. 21.

Una vez validado el instrumento de recogida de datos, se le envió a los docentes para su cumplimentación. En total, se han recogido un total de 21 docentes que utilizan de forma habitual recursos audiovisuales en sus aulas, algo que no es demasiado frecuente, incluso cuando se ha normalizado totalmente este recurso.Tras la recogida de los cuestionarios se procedió a la extracción de datos y posterior análisis. Los resultados se muestran a continuación.

\section{Resultados}

En primer lugar, el dato que nos gustaría resaltar fruto del análisis de los cuestionarios es el referente a la actitud de los docentes hacia el uso de los Recursos Audiovisuales en las aulas, en una muestra cuya experiencia docente tiene una media de 35 años. Estos docentes, que cuentan con un gran bagaje, muestran una actitud positiva $(57 \%)$ o altamente positiva (43\%) hacia su utilización; es decir docentes proactivos en este uso de los recursos audiovisuales en sus aulas, como herramientas para mejorar su docencia y, por tanto, para mejorar el proceso de enseñanza-aprendizaje. 
Igualmente, se puede comprobar que los docentes tienen conocimiento suficiente de la oferta de RAI así como de su uso en las aulas, pues al observar los datos se refleja que el $95 \%$ de los encuestados, usan estos recursos en sus aulas, reconociendo en un $100 \%$ de los casos que a lo largo de los años, el estado de conservación es de bueno a excelente; además, en un $95 \%$ de los casos reflejan que sus alumnos participan en el proceso de selección y sobre todo de producción de los RAI, y consideran que las exigencias didácticas que deben cumplir estos recursos son las que deben guiar su selección (91\%).

A su vez, para la selección y producción de los RAI, los docentes encuestados reflejan que lo hacen siempre pensando que son los más adecuados para los estudiantes $(86 \%)$, los mejores desde el punto de vista didáctico según ellos $(81 \%)$ y en muchas ocasiones $(71 \%)$ se tiene muy en cuenta el contenido, como era de esperar.

Así mismo la información nos indica que los docentes además de conocer lo referente a los RAI, también producen realizando una modificación del recurso, según las propias necesidades de sus estudiantes y el contenido que quieren trabajar, y tan solo un $18 \%$ de ellos, presenta ese recurso tal y como lo aportan las editoras.

Para confirmar lo manifestado anteriormente, también los docentes mejoran su formación para el mejor conocimiento y práctica en la selección, producción y uso de los RAI, asistiendo a talleres formativos según lo afirma un $91 \%$ de los docentes y solamente un 9\% no tiene formación alguna, ni ha asistido a ningún curso sobre el tema en cuestión.

La información obtenida también nos indica que los RAI se seleccionan o producen siempre de acuerdo con el programa vigente (57\%), aunque algunos reflejan que, en ocasiones, pueden variarlos por las propias necesidades de los estudiantes y no estar totalmente alineados con el programa a seguir (38,5\%). Además, al preguntar a los docentes si consideran que promueven dentro del programa habilidades personales y competencias, un $100 \%$ tienen la creencia de que sí.

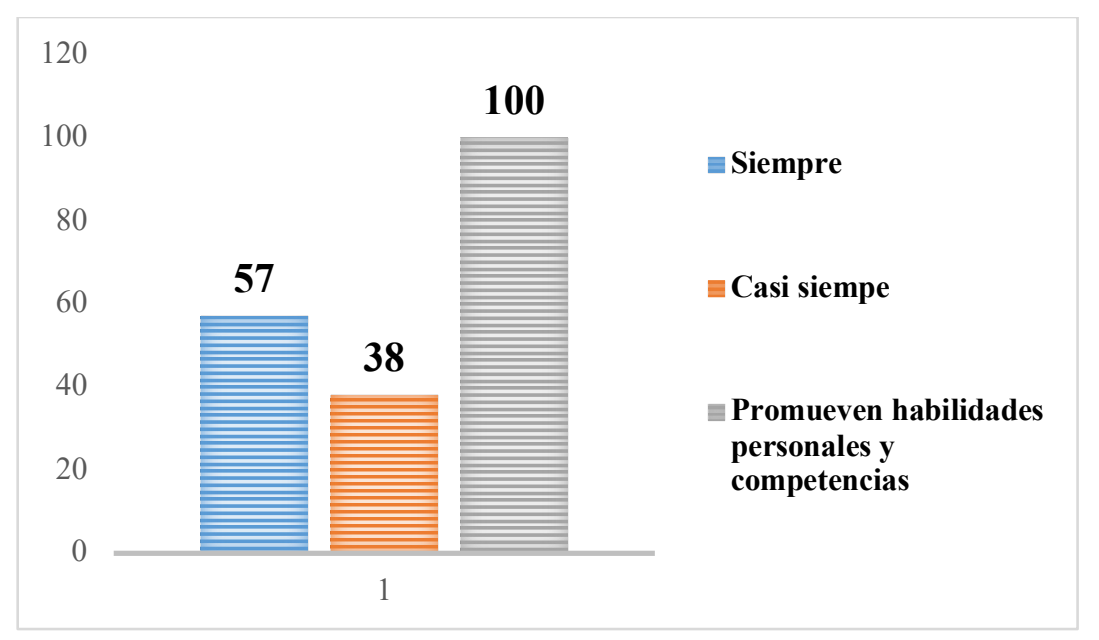

Figura 1. Los RAI de acuerdo con el Programa (\%). Fuente: elaboración propia.

Se puede corroborar también que, con el uso de los RAI, los docentes reconocen las competencias que tienen que desarrollar, así el 79\% manifiesta que se desarrollan las competencias de información y comunicación; el $88 \%$ manifiesta que se desarrollan las competencias de creación y el 100\% manifiesta que el uso de los RAI permite obtener resultados positivos. 


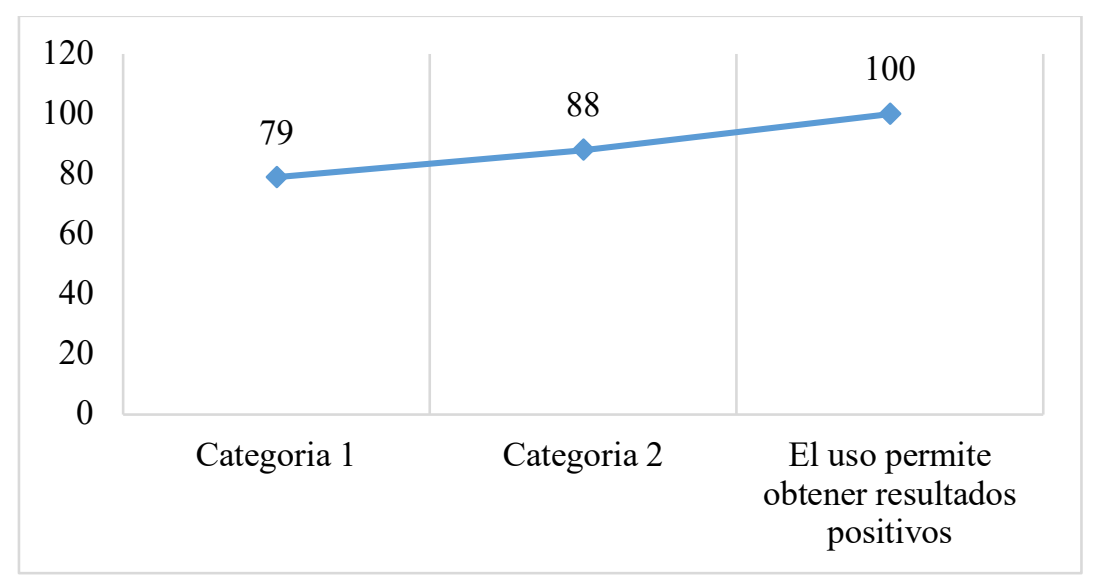

Figura 2. Todas las competencias a desarrollar (\%). Fuente: elaboración propia.

Los datos obtenidos demuestran que, con el uso de los RAI, se logra un mayor desarrollo de las competencias tal como lo demuestra el 95\% de los docentes.

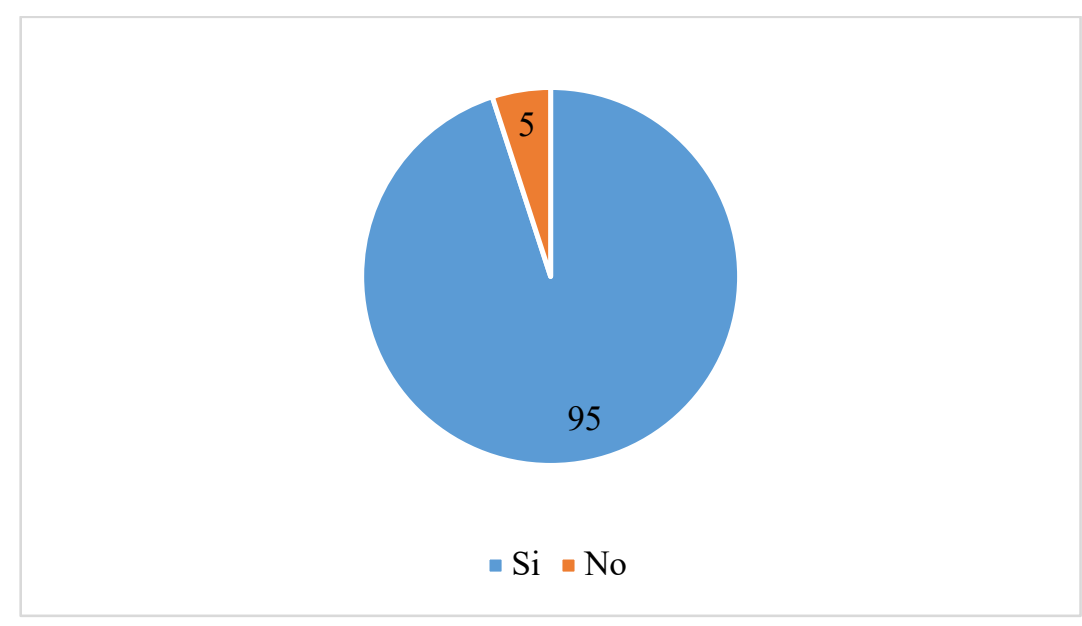

Figura 3. El uso de los RAI y desarrollo de Competencias (\%). Fuente: elaboración propia.

La información de que se dispone nos permite afirmar que el uso de los RAI, permite profundizar en los conocimientos, tal como manifiesta el $71 \%$ de los docentes que opinan que siempre se profundiza y el $29 \%$ de ellos que manifiestan que casi siempre lo hacen. 


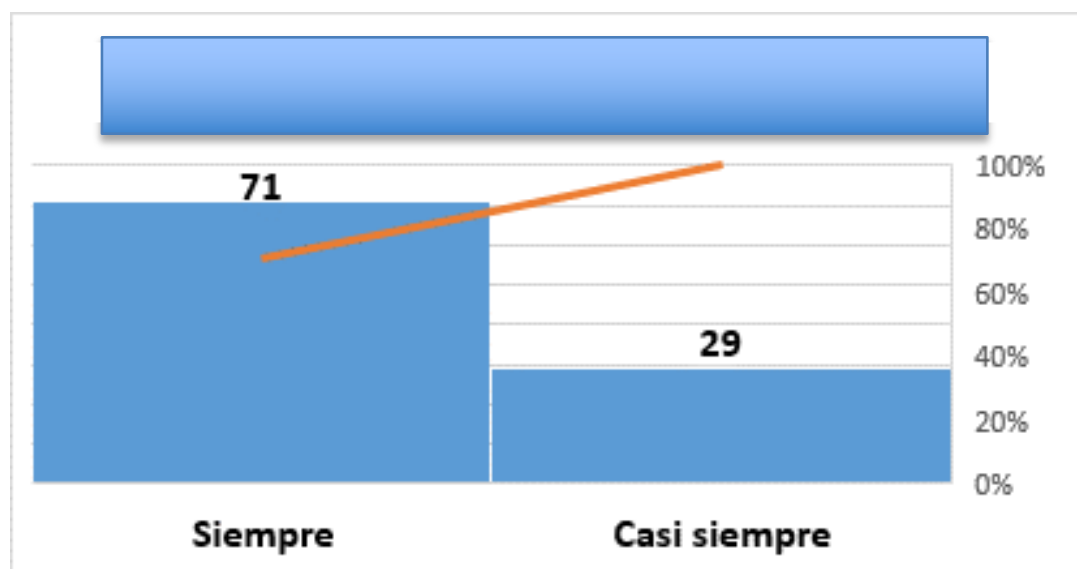

Figura 4. El uso de los RAI permite profundizar los conocimientos (\%). Fuente: elaboración propia.

De igual manera los datos nos indican que el uso de los RAI, generan en los alumnos capacidad de resolución de problemas, tal como lo afirma un $24 \%$ que dice siempre y un $62 \%$ casi siempre.

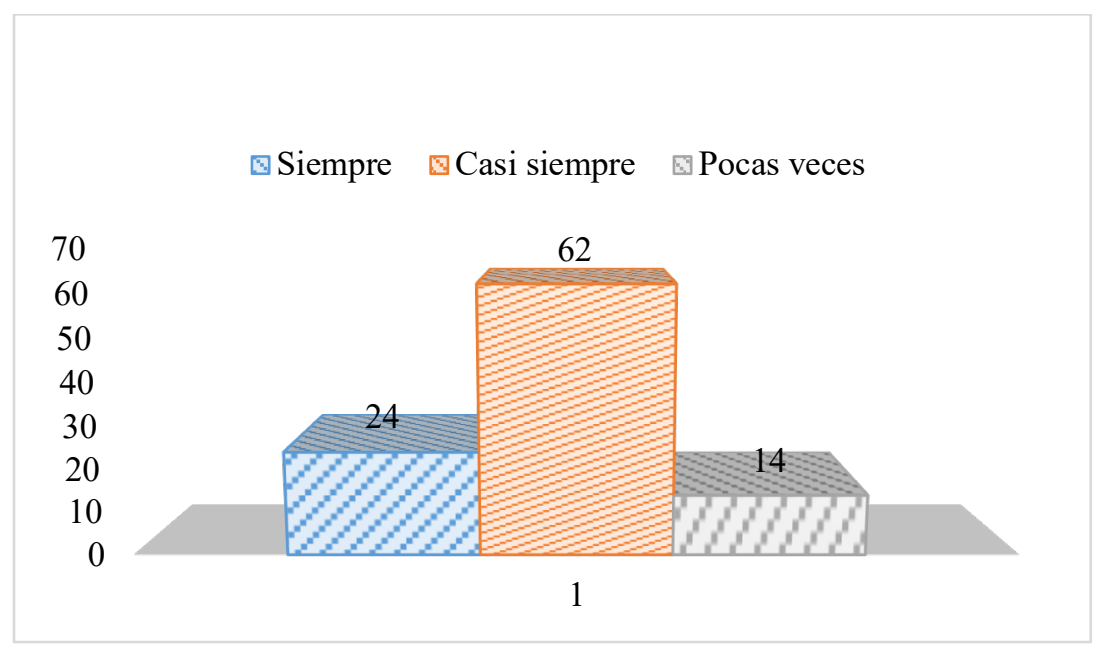

Figura 5. El uso de los RAI genera capacidad de resolución de problemas (\%). Fuente: elaboración propia.

Hasta ahora se han aportado los datos relativos a la primera dimensión medida en el cuestionario, la denominada "Conocimiento de los docentes de los Recursos Audiovisuales Interactivos (RAI)". A continuación pasaremos a mostrar los resultados que arrojan las preguntas de la segunda dimensión medida, denominada "Mejor desempeño laboral con el uso de los RAI".

Según la información obtenida, el uso de los RAI permite mejorar la dimensión laboral del docente, porque mejora su trabajo, según el $62 \%$ que está totalmente de acuerdo. 


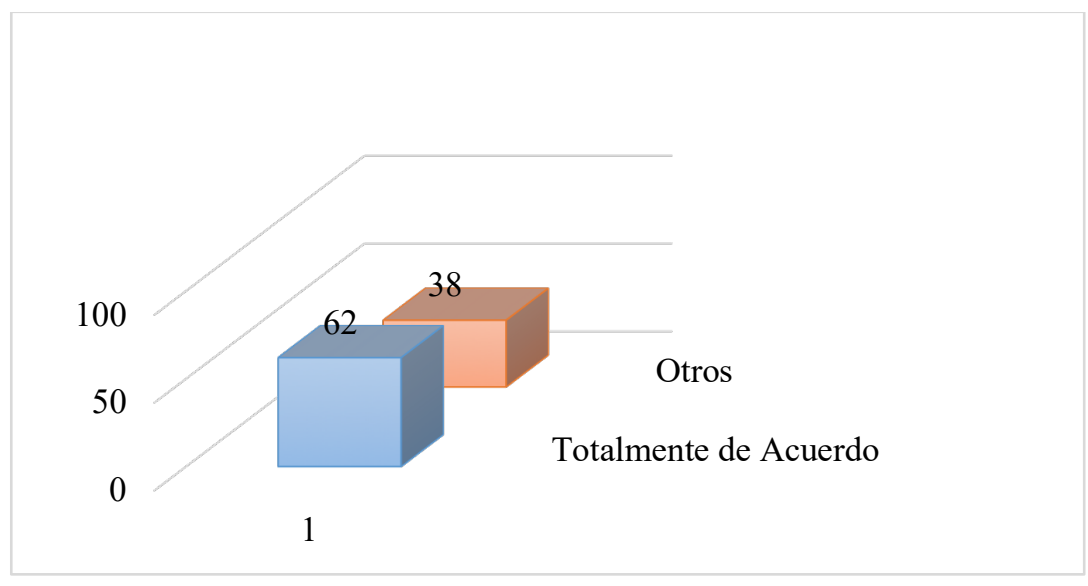

Figura 6. Mejora el trabajo Docente (\%). Fuente: elaboración propia.

Manifiestan también los docentes con un totalmente de acuerdo (52\%), que el uso de los RAI permite tener un mejor dominio de la asignatura.

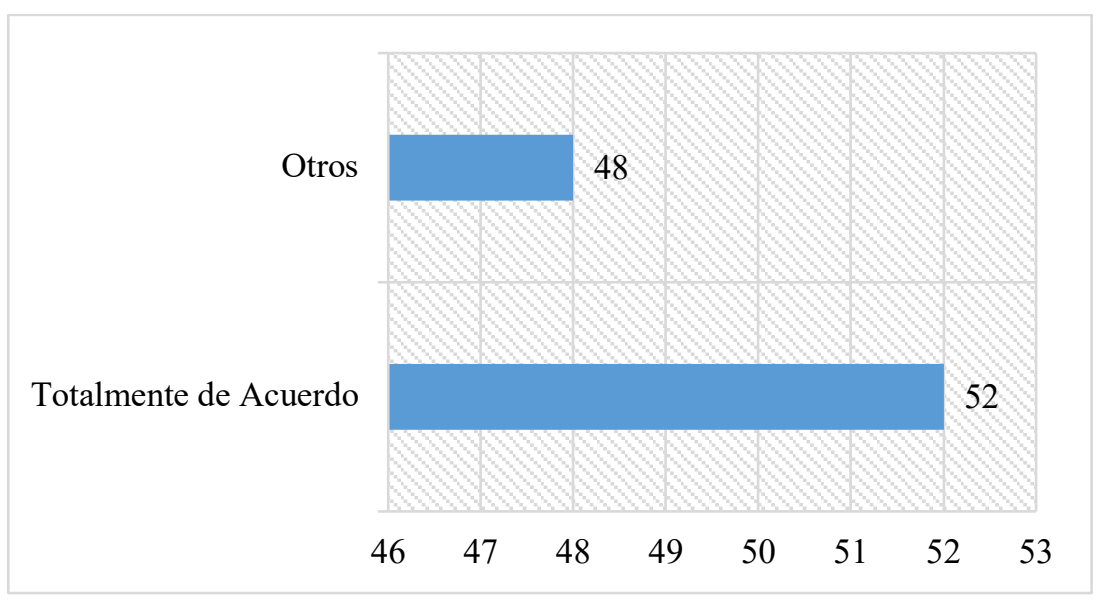

Figura 7. Permite tener mejor dominio de la asignatura (\%). Fuente: elaboración propia.

E1 $81 \%$ de los docentes dice estar preparado para el manejo técnico pedagógico de los RAI, con lo cual se confirma el mejoramiento del desempeño laboral del docente.

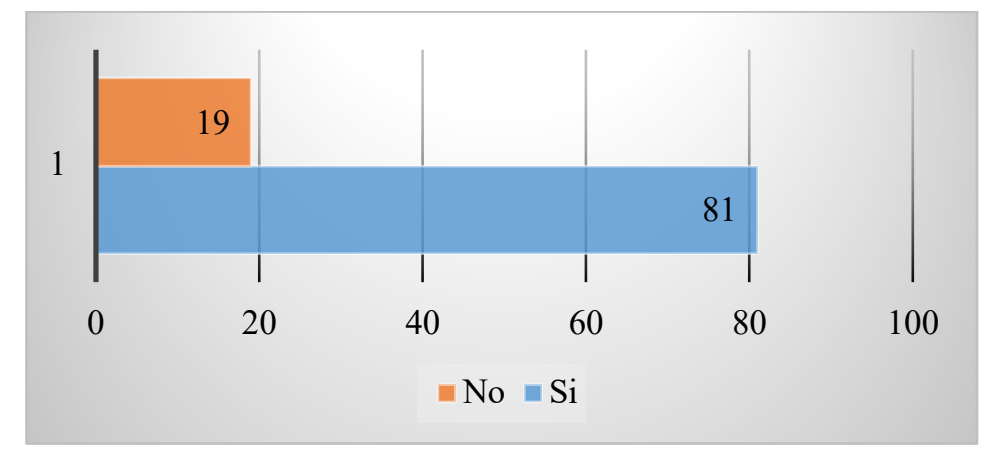

Figura 8. Preparación para el manejo técnico pedagógico de los RAI (\%). Fuente: elaboración propia. 
Para el mejor desempeño laboral, el uso de los RAI, facilitan el manejo o uso de nuevas estrategias docentes manifestado por el $48 \%$ de los docentes encuestados (siempre) y el $52 \%$ (casi siempre) de los mismos.

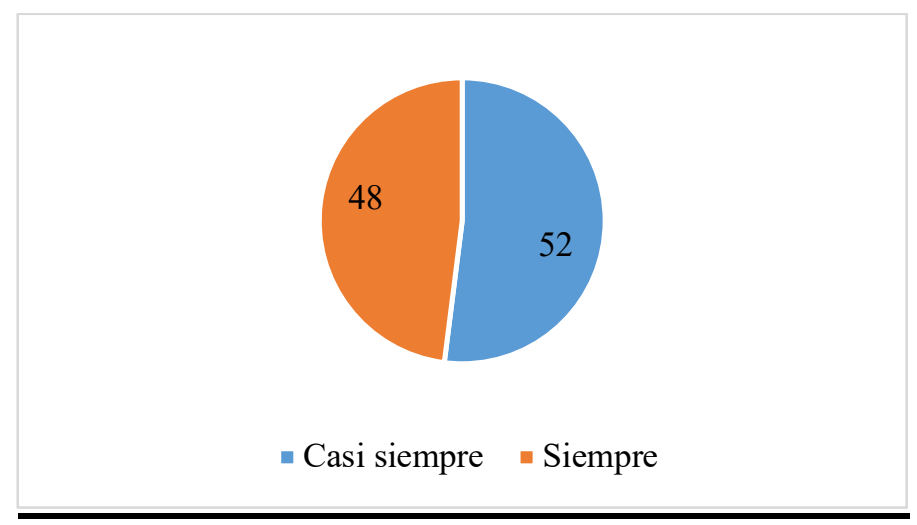

Figura 9. Facilitan el uso de nuevas estrategias de enseñanza (\%). Fuente: elaboración propia.

Otro de los aspectos que mejora el desempeño laboral de los docentes es porque el uso de los RAI, facilita el trabajo pedagógico según el 76\% de los encuestados que responden entre siempre y casi siempre.

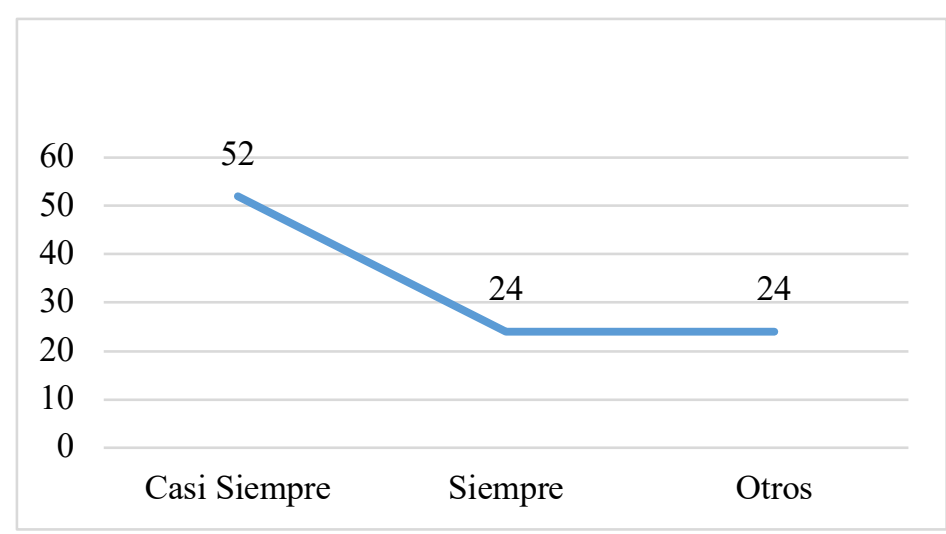

Figura 10. Facilitan el trabajo Pedagógico (\%). Fuente: elaboración propia.

También mejora el desempeño laboral del docente, el uso de los RAI, porque estos facilitan el autoaprendizaje e individualización de la enseñanza según el $81 \%$ de los decentes que responden entre siempre y casi siempre.

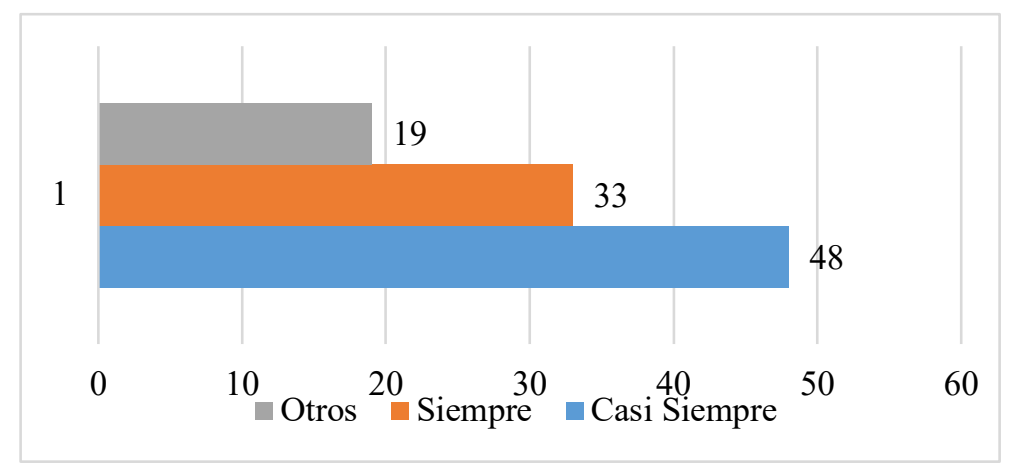

Figura 11. Facilita el autoaprendizaje e individualización de la enseñanza (\%). Fuente: elaboración propia. 
De igual forma, se mejora el desempeño laboral según el $96 \%$ de los docentes (siempre y casi siempre), porque el uso de los RAI permite combinar estrategias de enseñanza.

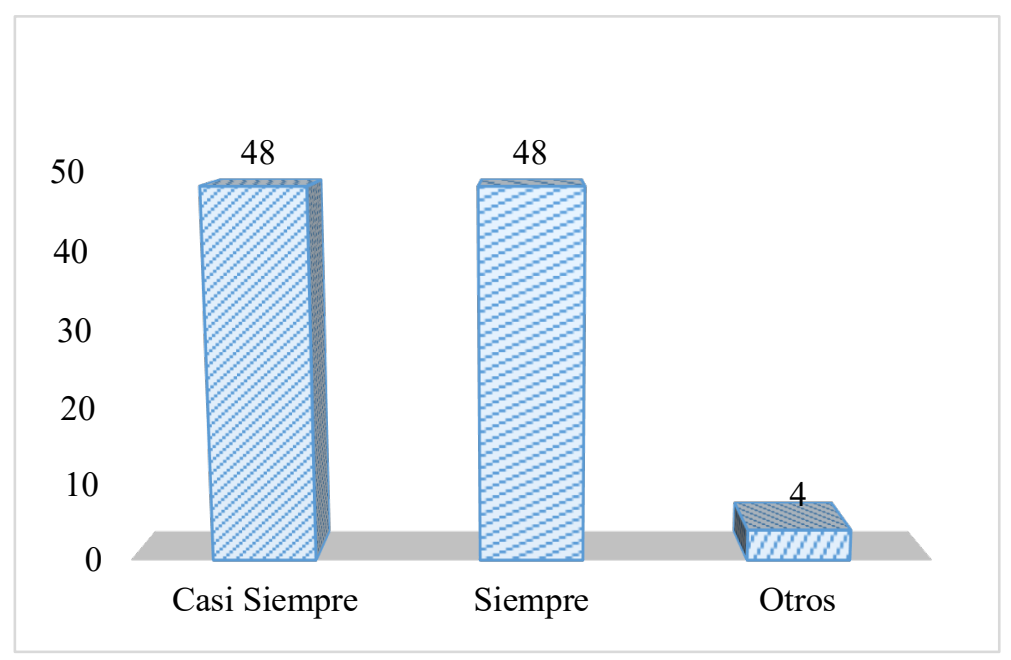

Figura 12. Permiten combinar estrategias de enseñanza (\%). Fuente: elaboración propia.

También se mejora esta dimensión según el 62\% de los encuestados, porque los usos de los RAI tienen al docente preparado para impartir educación audiovisual, es decir desarrollar la enseñanza basada en la presentación de materiales didácticos audiovisuales para favorecer los procesos de enseñanza y aprendizaje significativos y eficaces, tanto en entornos presenciales como virtuales.

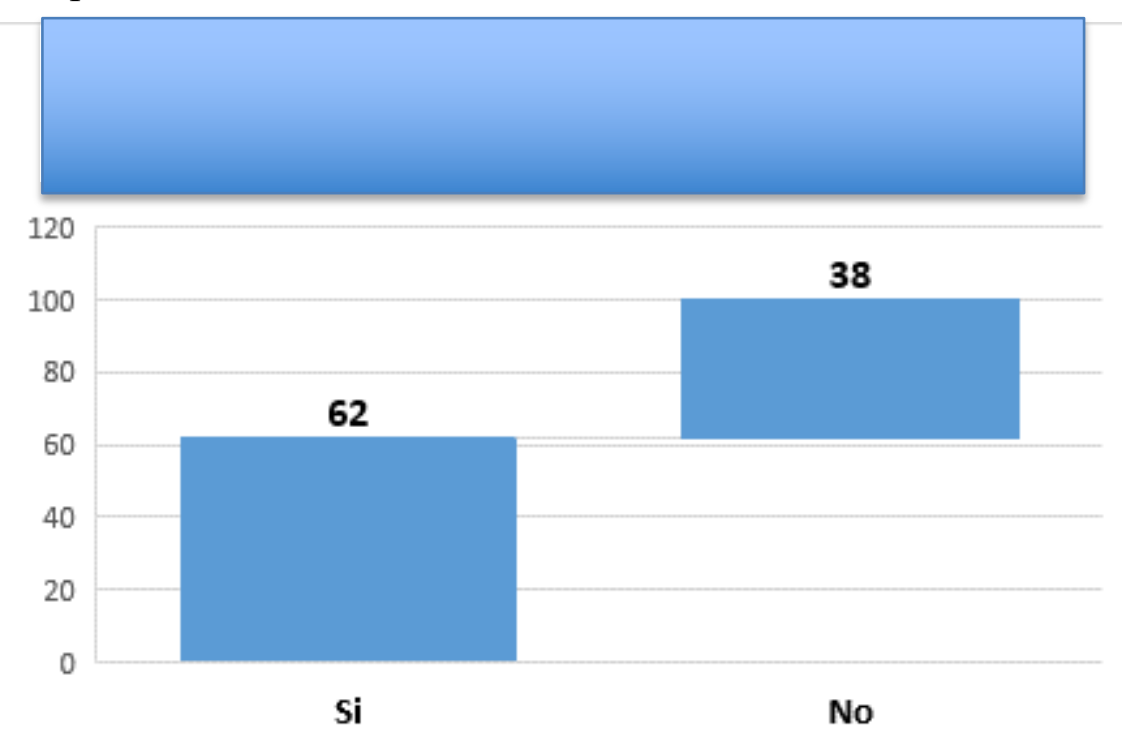

Figura 13. Dimensión mejora del desempeño laboral - el docente está preparado para impartir educación audiovisual (\%). Fuente: elaboración propia.

Para mejorar su desempeño laboral, los docentes han adquirido sus competencias con el uso de los RAI, principalmente por su propia iniciativa o apelando a la disponibilidad de recursos informáticos que contaban en casa y especialmente en la institución Educativa (76 \%) y con el apoyo en su centro laboral (14\%) y apenas un 10\% tiene conocimientos por su formación en la Universidad. 


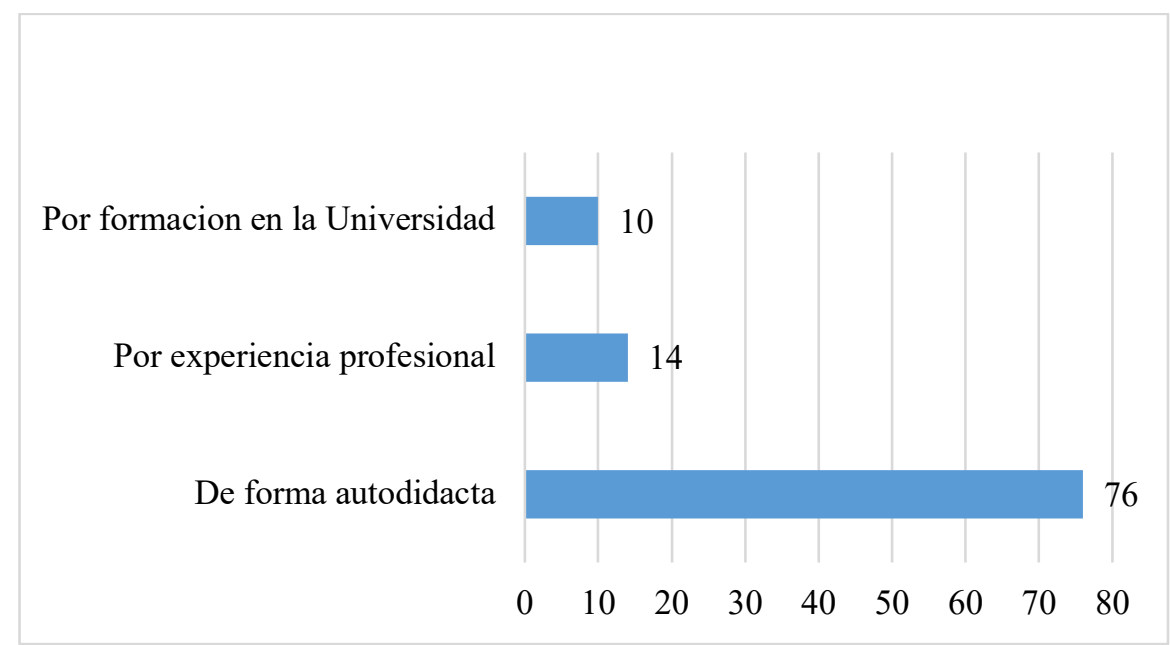

Figura 14. Por el trabajo con los RAI, los docentes han adquirido sus competencias (\%).

Fuente: elaboración propia.

La tercera dimensión evaluada en los cuestionarios es la denominada "Servicio eficiente" en la que se han medido tres grupos de cuestiones, las relacionadas con la capacidad del docente para usar los RAI, la propiedad intelectual de los recursos que deben respetar y compartir en todo momento y por último, las acciones realizadas para reforzar el servicio educativo.

Respecto al primer bloque, decir que este servicio eficiente que brinda el Centro educativo es gracias entre otros factores a la capacidad manifestada tener por parte de los docentes tales como que el 86\% delos docentes descargan, clasifican la información y contenidos digitales; el 95\% utilizan varios esquemas de clasificación para almacenar recursos; el $100 \%$ recupera y accede a la información y a los contenidos audiovisuales previamente; el 100\% etiqueta contenidos audiovisuales para tener un acceso más fácil posteriormente; el $57 \%$ organiza, gestiona y evalúa actividades de interacción con RAI; el 14\% participa mediante información acompañada de imágenes, enlaces y vídeos; el 95\% utiliza paquetes básicos de herramientas para crear contenidos en diferentes formatos; el $86 \%$ crea representaciones de conocimientos utilizando recursos digitales; el 91\% utiliza una amplia gama de recursos para expresarse de forma creativa y el $91 \%$ edita contenidos audiovisuales para mejorar el producto final. 


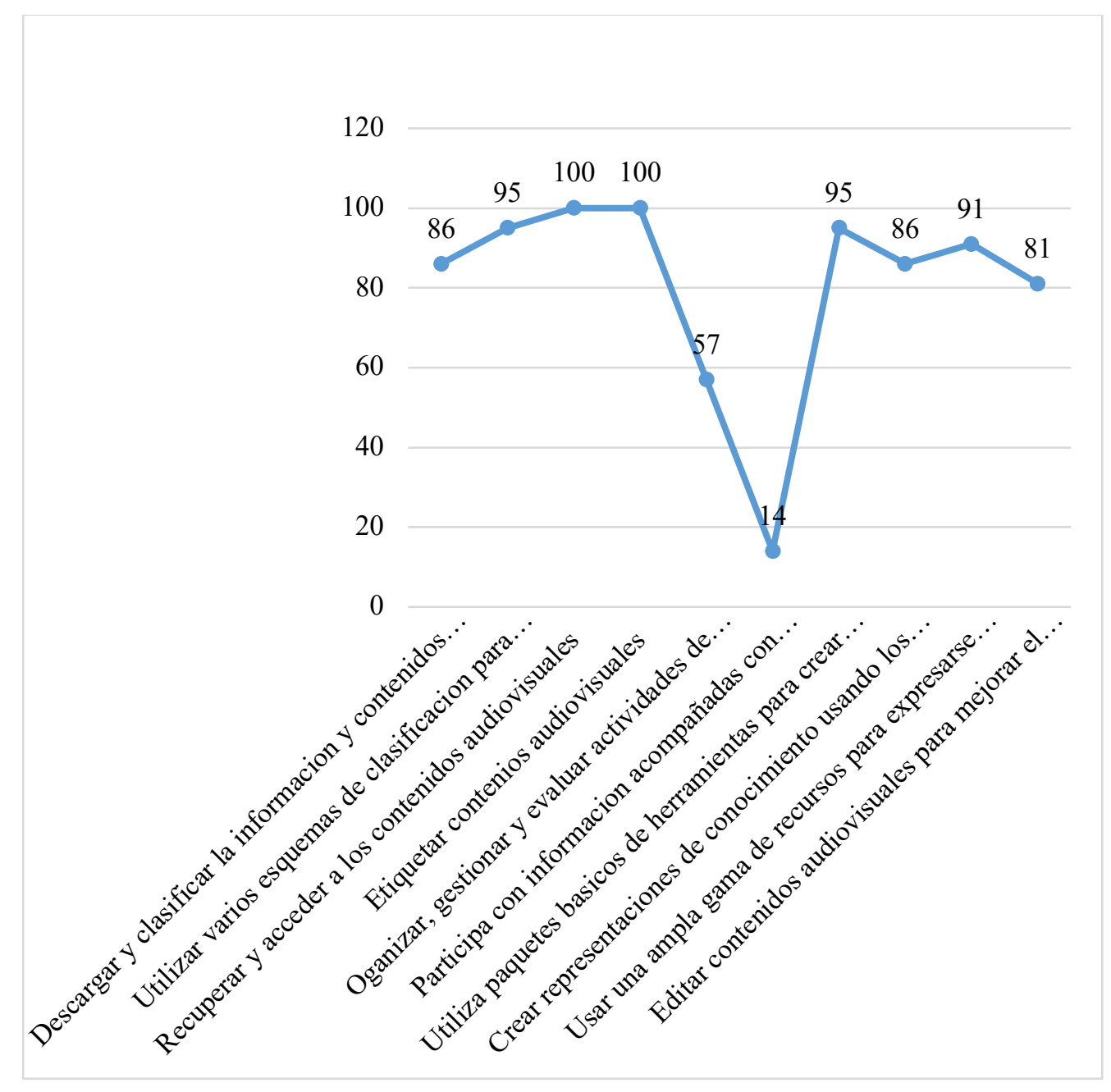

Figura 15. Capacidades del Docente (\%). Fuente: elaboración propia.

El servicio eficiente que brinda la institución educativa también se manifiesta por el respeto y conocimiento que tienen los docentes a la propiedad intelectual ya que el $81 \%$ de los docentes reconoce el derecho de propiedad o uso de los RAI; el 95\% comparten los contenidos encontrados en Internet y el 62\% utiliza las redes sociales para difundir resultados de sus trabajos. Desarrollados individualmente a nivel de: Tareas, Unidades de Aprendizaje o cursos en forma integral sin descuidar otro tipo de artículos relacionados a su área de trabajo.

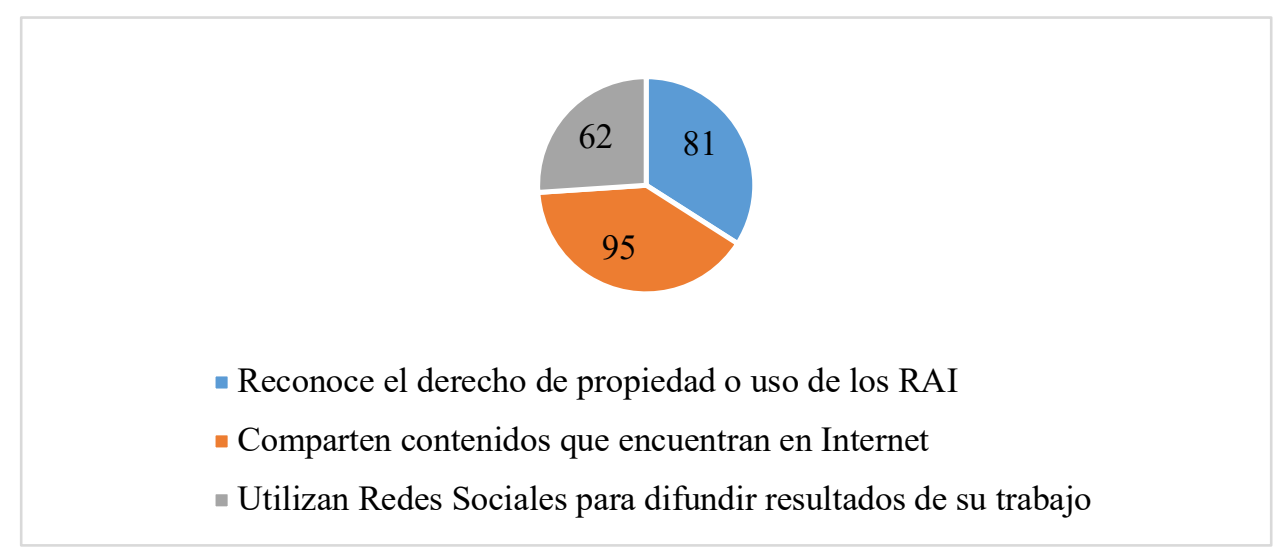

Figura 16. Propiedad Intelectual (\%). Fuente: elaboración propia. 
Por último, se confirma la dimensión servicio eficiente de la institución a través de acciones realizadas para reforzar este servicio, puesto que al preguntar a los docentes sobre qué acciones han llevado a cabo, manifiestan que el $91 \%$ ha creado programaciones didácticas que incluyen contenidos audiovisuales; el $91 \%$ ha potenciado la creación de recursos audiovisuales; el 95\% fomenta el uso de plataformas curriculares de recursos audiovisuales; el 81\% favorece y mejora el desarrollo curricular digital; el 95\% desarrolla estrategias de formación del docente; el 95\% desarrolla la integración de tecnología mediáticas; el 95\% potencia la alfabetización audiovisual; el $86 \%$ aprovecha las posibilidades legales para el uso de contenidos y los RAI; el 95\% facilita el desarrollo de licencias específicas para el uso de contenidos y los RAI y el 95\% favorece la experimentación, investigación e innovación mediante la interacción de los RAI.

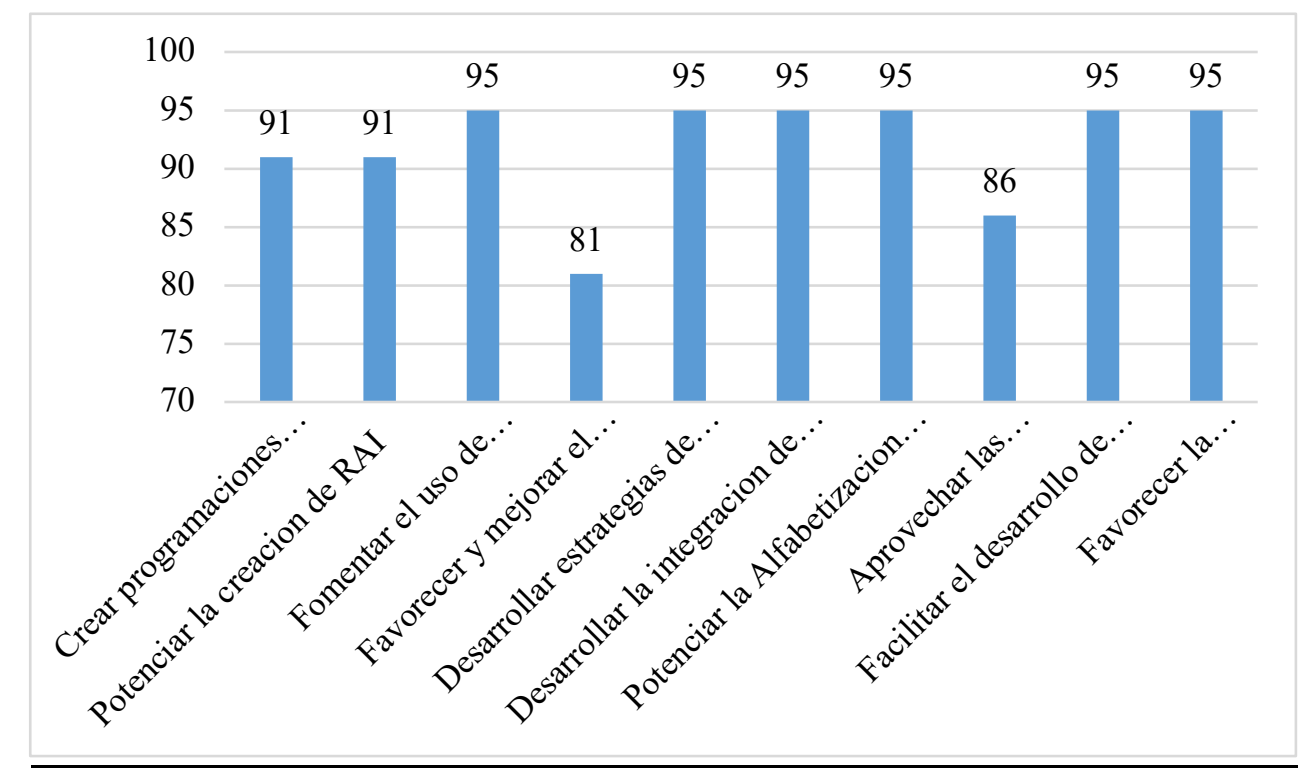

Figura 17. Dimensión: Servicio Eficiente - Acciones realizadas para reforzar el servicio (\%). Fuente: elaboración propia.

\section{Discusión y conclusiones}

Una vez presentados los datos que arrojaron los cuestionarios realizados por los docentes, y respondiendo a las preguntas iniciales que se hacían al inicio de este trabajo, se puede determinar que:

a) La incorporación sistemática y planificada del uso de los Recursos Audiovisuales Interactivos influye en el mejor funcionamiento académico de las instituciones estudiadas.

b) El mejoramiento del rendimiento escolar (académico) está influenciado por la utilización de los RAI.

c) El mejor desempeño, tener más facilidades y desarrollar capacidades del docente, están influenciados por el uso de estos recursos.

d)El uso de los RAI, influye en la Institución Educativa en la que se ponen en práctica para brindar un eficiente servicio educativo a la comunidad.

Por tanto, se puede decir que las dos hipótesis iniciales que se habían propuesto, se cumplen en su totalidad según los docentes que han sido encuestados, es decir, la 
identificación, selección y aplicación adecuada de las exigencias didácticas por los docentes en el diseño, producción y validación de los recursos audiovisuales interactivos didácticos determinan la eficacia con el consiguiente mejoramiento del rendimiento escolar y el uso programado de recursos audiovisuales interactivos didácticos, por los docentes, incide en una mayor eficacia para lograr un mayor rendimiento escolar y por consiguiente un mayor rendimiento del trabajo docente.

\section{Referencias}

Almerich, G.; Suárez, J.M.; Orellana, N. y Díaz, M.I. (2010). La relación entre la integración de las tecnologías de la información y comunicación y su conocimiento. Revista de InvestigaciónEducativa, 28 (1), 31-50.

Alonso, C. y Gallego, D.J. (2007). La videoconferencia como recurso en situaciones de enseñanza a distancia. En J. Cabero, F. Martínez. Y M.P. Prendes (Coord.). Profesor ¿estamos en el ciberespacio? Barcelona: Davinci.

Álvarez, M.T. (2014). Una experiencia audiovisual en el trabajo de adolescentes y jóvenes. Revista Sexología y Sociedad, 9 (22).

Área Moreira, M. (2000). La elaboración de módulos y materiales electrónicos para el $W W W$ en la educación de personas adultas. (Documento elaborado para la formación del profesorado del Proyecto Red VEDA (Red Virtual para la Educación de Adultos, 2000). Universidad de la Laguna.

Ballesteros Regaña, C. (2016). Los medios audiovisuales: funciones didácticas y principios metodológicos para su integración en los procesos de enseñanza y aprendizaje. Revista Internacional de Investigación e Innovación Educativa, 6, 58-70.

Barros Bastida, Carlos. (2015). Los Medios Audiovisuales y su influencia en la Educación desde las alternativas de análisis. Revista Universidad y Sociedad Vol7 № 3 . ISSN: $2818-3620$.

Chik, A. (2011). Learner Autonomy development throug digital gameplay.Digital Culture y Education, City University Oh Hong Kon,. 3(1), 41- 45.

De Andrés, T. Berlanga, A. Pérez, A. Segura, M. Ibarrondo, L. Cano, A. y Ga, Á. (2011). El desarrollo de la inteligencia filmica (Vol. 15). Ministerio de Educación.

Expósito, J. y Manzano, B. (2010). Tareas educativas interactivas, motivación y estrategias de aprendizaje, en Educación Primaria, a partir de un currículum modulado por nuevas tecnologías. TESI, 11(1), 330-351.

Expósito, J. y Manzano, B. (2013). Escuela TIC 2.0: Aprendizaje del alumnado de Primaria en su contexto educativo y socio familiar.EDUTEC, 45.

Fernández Botanero, M. (2010): Traducción y estudios actuales de Sociología de la Comunicación. Revista castellano - Manchega de Ciencias Sociales.

Fombona, J. Pascual, M.A. y Madeira, M.F. (2012). Realidad aumentada, una evolución de las aplicaciones de los dispositivos móviles. Pixel-Bit. Revista de Medios y Educación, 41, 197-210. Recuperado de http://idus.us.es/xmlui/handle/ 11441/22659gameplay. Digital Culture \&Education, 3(1), 30-45. 
Gallego J, F., Molina, R. y Faraón, L. (2014). Gamificar una propuesta docente diseñando experiencias positivas de aprendizaje. Universidad de Alicante.

García Matamoros, M.A. (2014). Uso Instruccional del video didáctico. Revista de investigación, 38 (81), 43 - 68.

García Valcárcel, A. (Coord.) (2015). Proyectos de trabajo colaborativo con TIC. Madrid: Síntesis.

García Valcárcel, A. Tejedor, F y Muñoz - Repiso. (2008). Competencias de los profesores para el uso de las TIC en la enseñanza. Análisis de sus conocimientos y actitudes. Revista Española de Pedagogía, Editor: Instituto Europeo de Iniciativas Educativas.

García Valcárcel, A. y Hernández, A. (2013). Recursos tecnológicos para la enseñanza e innovación educativa. Madrid: Síntesis.

García, A. R. Arellano, P. R. y Ruiz, M. R. G. (2014). Presencia de la competencia mediática en los objetivos curriculares de la etapa de educación primaria. Teoría de la Educación. Revista Interuniversitaria, 26 (1), 137-159.

García, M.L.S. y Nadal, C.C. (2015). El cine, recurso formativo. 18 años de investigación del grupo GIAD. Pixel-Bit. Revista de Medios y Educación, 46, 87-101.

Goig, M. (2009). Webquest: Proyecto colaborativo entre familia yescuela. I Simposio Internacional: "Buenas prácticas educativas conTIC. Málaga. 14-16 Diciembre 2009.

González García, M.G. (2015). Cine y literatura para el aprendizaje de las competencias básicas: vínculos semióticos y educativos. Educatio Siglo XXI, 33 (1), 175 - 194.

González, J. M. M. Cobo, I. L. y Rodríguez, R. S. (2014). El sistema de videoconferencia como herramienta para potenciar el aprendizaje colaborativo: En A. Hernández y S. Olmos (Coord.) Metodologías de aprendizaje colaborativo a través de las tecnologías. Salamanca: Ediciones Universidad de Salamanca.

Haan, J. (2011). Teaching and learning English through digital game projects. Digital Culture \&Education, 3(1), 46-55.

Hernández Martin, A. y Quintero Gallego, A. (2009). La integración de las TICen el currículo: necesidades formativas e interés del profesorado. RECEOP, 12 (2), $103-119$.

Lacasa, P. (2011). Los videojuegos. Aprender en mundos reales y virtuales. Madrid: Morata.

Manzano, B. (2012). Escuela TIC 2.0: Aprendizaje del alumnado dePrimaria en su contexto educativo y sociofamiliar. Granada: EditorialUniversidad de Granada.

Marín. M. (2008): Una gramática para todos, $1^{\circ} E d$., Buenos Aires, Voz activa.

Martínez, A. A. V. y Gómez, B. O. C. (2015). Evolución y análisis de una experiencia de utilización de videoconferencia de sala y de escritorio. Pixel -Bit: Revista de medios y educación, 47, 59 - 71.

Masalski, W. J. (2005). Preface. En, W. J. Masalski y P. C. Elliot (Eds.), Technologysupported mathematics learning environments. Sixty - SeventhYearbook. (p. ix). Reston, VA: NCTM.

Mesa Jacobo, J. R. (2015). Inteligencia Emocional, Rasgos de Personalidad e Inteligencia Psicométrica en Adolescentes. Universidad de Murcia. 
Moralejo, L. Sanz, C. V. Pesado, P. y Baldassarri, S. (2014). Avances en el diseño de una herramienta de autor para la creación de actividades educativas basadas en realidad aumentada. Libro de actas TE \& ET. Recuperado de http://www.teyet2014.undec.edu.ar/ Libro -deActasTEYET2014.pdf.

Pascual, M.A. y Ortega, J.A. (2007) Videojuegos y Educación. En J.A. Ortega y A. Chacón (coord.) Nuevas tecnologías para la educación en la era digital. Madrid: Pirámide.

Pellicer, P.B. (2014). Utilización didáctica del cine en matemáticas. Enseñanza \&Teaching, 32 (2), 123145.

Petit, M. F. y Solbes, J. (2015). El cine de ciencia ficción en las clases de ciencias de enseñanza secundaria (I). Propuesta didáctica. Revista Eureka sobre Enseñanza y Divulgación de las Ciencias, 12 (2), 311 - 327.

Prendes, M.P. y Castañeda, L.J. (2007). Aspectos pedagógicos de la videoconferencia. En J. Cabero, F. Martínez. y M.P. Prendes (Coord.). Profesor ¿estamos en el ciberespacio? Barcelona: Davinci.

Prieto, A., Díaz, D., Monserrat, J., y Reyes, E. (2014). Experiencias de aplicación de estrategias de gamificación a entornos de aprendizaje universitario. Revision, Vol 7, No 2, pp. 76-92.

Revuelta, F. I. y Esnaola, G. A. (Coord.) (2013). Videojuegos en redes sociales: Perspectivas del edutainment y la pedagogía lúdica en el aula. Barcelona: Laertes.

Sáez - López, J. M., y Ruiz - Gallardo, J. R. (2014). La enseñanza de las Ciencias Naturales y Sociales a través de la videoconferencia interactiva. Estudio de caso en Educación Primaria. Píxel - Bit, Revista de medios y educación, 44, 35 - 49.

Scolari, C. (ed.) (2013). Homo Videoludens 2.0. De Pacman a la gamification, Col-leccióTransmedia XXI. Barcelona: Laboratori de MitjansInteractius. Universitat de Barcelona.

Segura Morrero, A. (2016): La importancia de los Recursos Audiovisuales como herramienta educativa. Editor Universidad Isabel I, Burgos España.

Sigalés, C. Mominó, J. Meneses, J. y Badia, A. (2009). La integración de Internet en la educación escolar española: Situación actual y perspectivas de futuro. Barcelona: Ariel.

Somekh, B. (2007). Pedagogy and Learning with ICT. Researchingthe art of innovation. London: Routledge.

Tome Fernández, M. y Manzano García, B. (2015). Investigación en la Práctica Docente. Editorial Granada. Universidad de Zaragoza. Fundación Universitaria Antonio Cargallo. España. 
Fecha de recepción: 27/07/2019

Fecha de revisión: 18/11/2019

Fecha de aceptación: 08/01/2020 